Check for updates

Cite this: Mater. Adv., 2020 1,1220

Received 6th April 2020,

Accepted 21st June 2020

DOI: 10.1039/d0ma00169d

rsc.li/materials-advances

\section{Enhancement of $\gamma$-radiation stability of polysulfone membrane matrix by reinforcement of hybrid nanomaterials of nanodiamond and ceria $\dagger$}

\author{
Amita Bedar, (D) ab Raja K. Lenka, ${ }^{c}$ Narender K. Goel, ${ }^{\text {a }}$ Sanjay Kumar, ${ }^{e}$ \\ Ratnesh D. Jain, ${ }^{f}$ Beena G. Singh, ${ }^{9}$ Pradip K. Tewari, ${ }^{a}$ Ramesh C. Bindal $^{\mathrm{ab}}$ and \\ Soumitra Kar iD *ab
}

\begin{abstract}
For the first time, a hybrid nanoparticle system of nanodiamond (ND) and cerium oxide (ceria) is used as a reinforcement material in order to enhance the $\gamma$-radiation stability of polysulfone (Psf) host membrane matrix. Control Psf and Psf-(ND + Ce) hybrid membranes are synthesized and characterized, with the loading of each nanomaterial varying from 0.25 to $0.5 \mathrm{wt} \%$. The membranes are exposed to $\gamma$-radiation at different doses (up to $1000 \mathrm{kGy}$ ) and the effect of radiation on the Psf matrix is evaluated. Gel permeation chromatography studies confirm that the average molecular weight of the hybrid membranes is restored to a reasonable extent, in contrast to the control Psf membrane, which is reduced by $45 \%$ at a radiation dose of $1000 \mathrm{kGy}$. The optimum loading of ND and ceria in the membrane matrix is found to be $0.5 \%$ each, which offers a remarkable $\sim 10$-fold enhancement of radiation stability compared to the control Psf membrane, making it a novel membrane material for potential applications in radioactive environments. The enhanced stability of the optimum hybrid membrane is due to the ability of ND and ceria in scavenging the secondary $\mathrm{e}_{\mathrm{aq}}{ }^{-}$and $\mathrm{OH}^{\bullet}$ radicals, respectively, generated due to the radiolysis of water, as confirmed by the free radical scavenging studies.
\end{abstract}

\section{Introduction}

Polymeric membranes have a wide range of applications including water and wastewater treatment, ${ }^{1,2}$ fuel cell applications, ${ }^{3}$ gas separation, ${ }^{4}$ haemodialysis,${ }^{5}$ sensors, ${ }^{6}$ industrial effluent treatment, ${ }^{7}$ etc. They have received extensive attention due to their reproducible properties, such as mechanical strength, flexibility, thermal stability, negligible secondary waste generation, as well as low cost availability. ${ }^{8}$ In the nuclear industry, during

\footnotetext{
${ }^{a}$ Homi Bhabha National Institute, Mumbai - 400094, India.

E-mail:soubiswa@barc.gov.in, soumitra.1stmay@gmail.com

${ }^{b}$ Membrane Development Section, Bhabha Atomic Research Centre, Trombay, Mumbai - 400085, India

'Powder Metallurgy Division, Bhabha Atomic Research Centre, Trombay, Mumbai - 400085, India

${ }^{d}$ Radiation Technology Development Division, Bhabha Atomic Research Centre, Trombay, Mumbai - 400085, India

${ }^{e}$ Material Science Division, Bhabha Atomic Research Centre, Trombay, Mumbai - 400085, India

${ }^{f}$ Department of Chemical Engineering, Institute of Chemical Technology, Mumbai - 400019, India

${ }^{g}$ Radiation \& Photochemistry Division, Bhabha Atomic Research Centre, Trombay, Mumbai - 400085, India

† Electronic supplementary information (ESI) available. See DOI: 10.1039/ d0ma00169d
}

various stages of the nuclear fuel cycle, a large amount of radioactive effluent is generated and there is a need for safe and effective management of these effluents. ${ }^{9}$ Materials used for such treatments should be stable in radioactive environments. Polysulfone (Psf) stands out as a remarkable polymer among thermoplastic polymers by virtue of its usability at high temperature and pressure, as well as its chemical inertness. ${ }^{10}$ Psf has reasonably high strength and a high glass transition temperature due its aromatic backbone, ${ }^{11}$ while being resistant towards radiation. ${ }^{12}$ Hence, it is the preferred choice for working in challenging environments, such as nuclear waste treatment ${ }^{13}$ and spacecraft applications. ${ }^{14}$

Psf is a commonly used polymeric material for membrane fabrication. Not many studies have investigated the effects of radiation on Psf membranes, while some researchers have reported that both cross-linking and chain-scission of Psf take place when the membrane is exposed to $\gamma$-rays. ${ }^{15,16}$ Moreover, the radiolysis of water produces highly reactive free radicals under $\gamma$-radiation. ${ }^{17}$ The free radicals induced by $\gamma$-ray irradiation lead to accelerated chain scissioning and cross-linking of Psf, leading to the disintegration of the polymer host matrix, as well as the performance degradation of the membrane. Considering the above findings, there is extensive interest in establishing systems which can prevent the degradation of the 
Psf membrane matrix by $\gamma$-radiation, as well as trap in situ the free radicals generated due to the $\gamma$-radiolysis of water.

Nanomaterials possess unique properties, such as high surface area, high mechanical strength, tunability, low density, high porosity, resistance to harsh environments, etc. ${ }^{18-22}$ These properties offer unprecedented opportunities to tailor-make membranes with desirable attributes for the target applications. ${ }^{23-30}$ Nanodiamond (ND) has been found to be a distinctive filler material for composite membranes by virtue of its mechanical and thermal properties, as well as superior surface chemistry. Furthermore, the incorporation of ND in polymers revealed significant enhancement of the mechanical strength, wear resistance, adhesion, electromagnetic shielding and thermal conductivity of the polymers. ${ }^{31}$ On the other hand, a cerium atom displays feasible conversion between $\mathrm{Ce}^{4+}$ and $\mathrm{Ce}^{3+}$. An oxygen vacancy is also created, transferred and eliminated in sync with a cerium atom. ${ }^{32}$ This property of cerium improves the absorption of reactive oxygen radicals and promotes electron transfer. Moreover, cerium oxide (ceria) nanoparticles can act as radiation absorbers. ${ }^{33}$ This is suggested by the fact that ceria is known for shielding against $\gamma$-rays by its $\mathrm{K}$ absorbance boundary in the 40 to $80 \mathrm{kV}$ voltage range. $^{34}$

In order to develop radiation resistant membranes, in our previous work, nanocomposite polymeric membranes were developed by the reinforcement of ceria in the Psf host matrix, ${ }^{35}$ wherein the free radical scavenging property of ceria resulted in $\sim 5$-fold enhanced radiation stability of the Psf-ceria composite membrane, compared to the control Psf membrane. Similar findings were obtained with impregnation of ND. ${ }^{36}$ However, these composite membranes lose their stability above a radiation dose of $500 \mathrm{kGy}$. In the present study, in order to further increase the lifetime of the membrane in a radiation environment through stabilizing the membrane structure and providing mechanical strength to the membrane, ND and ceria together were considered as a hybrid filler material in the Psf membrane matrix. In order to exploit the properties and take on board the synergistic effects of both the nanomaterials (ND and ceria), for the first time, hybrid nanocomposite membranes [Psf-(ND + Ce)] are developed and their stability in $\gamma$-radiation environments is evaluated. Compared to the control Psf membrane, the hybrid membranes are found to offer $\sim 10$-fold enhanced radiation stability. It has also been confirmed that the hybrid membranes reinforced with $0.5 \mathrm{wt} \% \mathrm{ND}$ and $0.5 \mathrm{wt} \%$ ceria are about 2 times more stable as compared to the membranes impregnated with $0.5 \mathrm{wt} \%$ of ND or ceria alone. To the best of our knowledge, this is the first study of its kind undertaken that highlights the importance of the reinforcement of hybrid nanomaterials for significant enhancement of the radiation resistant attributes of a polymer membrane.

\section{Experimental}

\subsection{Materials}

Details of the materials procured for experimentation are given below.

(1) AR-grade cerium nitrate $\left(\mathrm{Ce}\left(\mathrm{NO}_{3}\right)_{3} \cdot 6 \mathrm{H}_{2} \mathrm{O}\right)$ with purity $>99.9 \%$ was obtained from Indian Rare Earth Limited, India.

(2) Citric acid $\left(\mathrm{C}_{6} \mathrm{H}_{8} \mathrm{O}_{7} \cdot \mathrm{H}_{2} \mathrm{O}\right)$ of purity $>99 \%$ was procured from Merck, India.

(3) Nanodiamond powder (ND, particle size $<10 \mathrm{~nm}$ (Fig. S1, ESI, $\dagger$ Section S1), assay $\geq 97 \%$, MW: $12.01 \mathrm{~g} \mathrm{~mol}^{-1}$, density: $3.5 \mathrm{~g} \mathrm{ml}^{-1}$ ) was procured from Sigma-Aldrich.

(4) Polysulfone (Psf) (molecular weight: $60 \mathrm{kDa}$ ) was procured from Solvay Specialties India Pvt. Ltd, India.

(5) $N$-Methyl-2-pyrrolidone (NMP) (assay $\geq 99.5 \%$ ) was purchased from SRL Pvt. Ltd, Mumbai, India.

(6) Polyvinyl pyrrolidone (PVP) (K-30; molecular weight: $40 \mathrm{kDa})$ of AR grade was purchased from SRL Pvt. Ltd, Mumbai, India.

(7) Polyethylene oxide (PEO) (molecular weight: $100 \mathrm{kDa}$ ) was procured from Sigma-Aldrich.

\subsection{Preparation of ceria nanoparticles}

Cerium oxide (ceria) nanoparticles were prepared by a gelcombustion method, using cerium nitrate as an oxidant and citric acid as a fuel. In this method, a pre-calculated amount of cerium nitrate and citric acid was initially dissolved in de-ionized water and then dehydrated at $120{ }^{\circ} \mathrm{C}$ to form a gel precursor. Later, the temperature was further increased to $200{ }^{\circ} \mathrm{C}$, which resulted in auto ignition of the gel precursor, leading to the formation of cerium oxide nanoparticles. The fabricated powder was then calcined at $700{ }^{\circ} \mathrm{C}$ for $1 \mathrm{~h}$ to remove residual carbonaceous products. The calcination process resulted in the formation of pure, crystalline ceria nanoparticles of $12 \mathrm{~nm}$ average particle size (Fig. S2, ESI, $\dagger$ Section S1). Further description of the preparation and characterization of cerium oxide nanoparticles is given in our earlier work. ${ }^{35}$

\subsection{Preparation of control Psf and Psf-(ND + Ce) hybrid membranes}

Control Psf and Psf-(ND + Ce) hybrid membranes were fabricated by a phase inversion technique. For fabricating these membranes, dope solutions were prepared as per the compositions provided in Table 1. For the Psf-(ND + Ce) hybrid membranes, ND and ceria

Table 1 Compositions of dope solutions for membrane synthesis

\begin{tabular}{|c|c|c|c|c|c|c|}
\hline Type of membrane & Membrane label & Psf $(g)$ & NMP (ml) & PVP (g) & ND (\%/Psf) & Ceria (\%/Psf) \\
\hline Control Psf & Psf & 25 & 100 & 7.5 & 0 & 0 \\
\hline \multirow[t]{4}{*}{ Psf-(ND + Ce) hybrid } & $0.25 \mathrm{ND}-0.25 \mathrm{Ce}$ & 25 & 100 & 7.5 & 0.25 & 0.25 \\
\hline & $0.25 \mathrm{ND}-0.5 \mathrm{Ce}$ & 25 & 100 & 7.5 & 0.25 & 0.5 \\
\hline & $0.5 \mathrm{ND}-0.25 \mathrm{Ce}$ & 25 & 100 & 7.5 & 0.5 & 0.25 \\
\hline & $0.5 \mathrm{ND}-0.5 \mathrm{Ce}$ & 25 & 100 & 7.5 & 0.5 & 0.5 \\
\hline
\end{tabular}


were mixed in the proportions given in Table 1 . The nanomaterials were then dispersed in $100 \mathrm{ml}$ of NMP and kept in a sonication bath for 30 minutes. The base polymer, Psf (25 g), and additive PVP $(7.5 \mathrm{~g})$ were then added to the dispersion. The dope solution was stirred continuously until a homogeneous casting solution was obtained. The stirring process usually took up to $24 \mathrm{~h}$. The dope solution for the control Psf membrane was prepared without the addition of any nano additives, following the same procedure.

Both control Psf and Psf-(ND + Ce) hybrid membranes with a thickness of $200 \mu \mathrm{m}$ were prepared using a flat-sheet table top casting machine at ambient temperature and then gelled in demineralized water. The compositions and labels of different membranes are given in Table 1.

\subsection{Irradiation of membranes}

The as-prepared individual membranes immersed in demineralized water were sealed in zip-lock polyethylene bags for irradiation. Both control Psf and Psf-(ND + Ce) hybrid membranes were exposed to 100, 500 and $1000 \mathrm{kGy}$ of radiation using a ${ }^{60}$ Co source Gamma Chamber GC-5000 (Board of Radiation \& Isotope Technology, BRIT, India) with a dose rate of about $1.5 \mathrm{kGy} \mathrm{h}^{-1}$ (Fricke dosimetry).

\subsection{Membrane characterization}

The surface and cross-sectional morphology of the membranes was observed using field-emission scanning electron microscopy (FE-SEM, AURIGA 4553) at operating voltages of 20 and $5 \mathrm{kV}$, respectively. Using a sputter coater with a gold-palladium alloy target, the membranes were made electrically conducting at $15 \mathrm{~mA}$ current for 100 seconds.

The average pore size of the membranes was determined using a porometer (Porolux 1000 model, Benelux Scientific, Belgium). The data acquisition and analysis was carried out using LabView software for the $25 \mathrm{~mm}$ diameter of membrane sample. The "Porefil" solution (Benelux Scientific, Belgium, $\gamma=16$ dyne $\mathrm{cm}^{-1}$, vapour pressure $=3 \mathrm{~mm} \mathrm{Hg}$ at $298 \mathrm{~K}$ ) was used as a wetting liquid for capillary flow porometry, as it is a non-toxic and inert fluorocarbon wetting fluid with zero contact angle in the membrane, that is $\cos \theta=1$.

The topography of the membrane surface was analyzed through atomic force microscopy (AFM, SOLVER next, NT-MDT, Russia). For AFM analysis, a small $\left(1 \mathrm{~cm}^{2}\right)$ dry piece of membrane was taken and pasted onto the metal substrate. AFM images were obtained in tapping mode using a silicon cantilever NSG 10 (NT-MDT, Russia) with a spring constant of $11.8 \mathrm{~N} \mathrm{~m}^{-1}$ and resonating frequency of $240 \mathrm{kHz}$. The imaging was carried out at room temperature and ambient pressure, and the surface roughness of these membranes was obtained by NOVA-P9 software. The effect of nanomaterial (ND and ceria) loading and irradiation dose on the surface roughness of the membrane was examined within a scan range of $3 \mu \mathrm{m} \times 3 \mu \mathrm{m}$.

Using KRUSS Advance drop shape analyzer (DSA100, Germany), the water contact angle at the membrane surface was measured under ambient conditions. A small piece of membrane was placed on a glass slide and water was dropped onto the surface of the membrane. The drop was illuminated from one side and a camera at the opposite side recorded an image of the drop. KRUSS Advance software was used to analyze the image. Contact angles were measured in three different regions on each membrane and an average was taken.

A gel permeation chromatography (GPC) system (Malvern 270 dual detector, UK) equipped with a refractive index detector and light scattering detector $(\lambda=670 \mathrm{~nm}$, consisting of two scattering angles: $7^{\circ}$ and $90^{\circ}$ ), along with T6000M, a general mixed organic column $(300 \times 8 \mathrm{~mm})$ (Viscotek, Malvern, UK), was used to determine the average molecular weight of the membrane samples. The detector and column temperature was kept at $22{ }^{\circ} \mathrm{C}$. The mobile phase consisted of tetrahydrofuran (SD Fine Chemicals Ltd, India) at a flow rate of $0.5 \mathrm{ml} \mathrm{min} \mathrm{m}^{-1}$. A PTFE syringe filter with $0.22 \mu \mathrm{m}$ pore size and $25 \mathrm{~mm}$ diameter (AxivaSichem Biotech, India) was used to filter the samples. The volume injected was $100 \mu \mathrm{l}$. Both detectors were calibrated with polystyrene standards with a narrow molecularweight distribution. Viscotek OmniSEC 5.12 software was used to analyze the data.

Differential scanning calorimetry (DSC) thermograms of unirradiated and $1000 \mathrm{kGy}$ irradiated membranes were recorded in a differential scanning calorimetry unit (DSC 1 STARe system, Mettler-Toledo AG (MTANA), Switzerland) over the temperature range of 40 to $600{ }^{\circ} \mathrm{C}$ in flowing oxygen atmosphere (flow rate: $40 \mathrm{ml} \mathrm{min}^{-1}$ ). The DSC unit was calibrated for temperature and heat flow measurements using multiple standards ( $\mathrm{Hg}, \mathrm{In}, \mathrm{Sn}, \mathrm{Pb}$ and $\mathrm{Zn}$ ) prior to measurements. For the DSC measurement, a small piece of each membrane was sealed in the $40 \mu \mathrm{l}$ aluminium pan by covering it with a lid with a small hole in it.

A universal testing machine (UTM, Hemetek Techno Instrument, LRX Plus, India) was used to measure the mechanical properties of the membranes at room temperature and $40-50 \%$ relative humidity. Dumbbell-shaped specimens of the membranes, each of $5 \mathrm{~cm}$ length and $0.6 \mathrm{~cm}$ width, were prepared for analysis. During the analysis, a constant deformation rate of $100 \mathrm{~mm} \mathrm{~min}^{-1}$ was applied. NEXYGEN plus software was used to calculate the tensile strength (TS) and percent elongation at maximum force $(\% E)$ for the membrane.

\subsection{Membrane performance evaluation}

The performance of the membranes was studied in an ultrafiltration test skid (cross-sectional area $A=14.5 \mathrm{~cm}^{2}$ ) at room temperature and 1 bar trans-membrane pressure. Steady state pure water permeability (PWP) was established by measuring the flow of the permeate in litres per square meter per hour $\left(\mathrm{L} \mathrm{m}^{-2} \mathrm{~h}^{-1}\right)$. PWP through the membrane area $\left(A\right.$, in $\left.\mathrm{m}^{2}\right)$ was calculated using the volume $(V$, in $\mathrm{L})$ collected during a time period ( $T$, in $\mathrm{h}$ ) and expressed as eqn (1).

$$
\mathrm{PWP}=\frac{V}{A \times T}
$$

The membranes were initially placed in water for $1 \mathrm{~h}$ for compaction under standard ultrafiltration test conditions to achieve stabilized performance. The solute rejection behavior of the membranes was studied using $200 \mathrm{ppm}$ solutions of 
polyethylene oxide (PEO, average molecular weight $100 \mathrm{kDa}$ ) at room temperature and 1 bar trans-membrane pressure. A TOC analyzer (ANATOC, SGE analytical science, Australia) was used to analyze the concentration of PEO in both feed and permeate samples by measuring the total organic carbon content. The rejection $(R)$ of PEO offered by the membranes was calculated using eqn (2).

$$
R(\%)=\frac{C_{\mathrm{f}}-C_{\mathrm{p}}}{C_{\mathrm{f}}} \times 100
$$

Here, $C_{\mathrm{f}}$ is the concentration in the feed and $C_{\mathrm{p}}$ is the concentration in the permeate.

\subsection{Pulse radiolysis studies for evaluation of $\mathrm{e}_{\mathrm{aq}}{ }^{-}$scavenging capability of ND particles}

Pulse radiolysis experiments were carried out with high-energy electron pulses (7 MeV, $500 \mathrm{~ns}$ ) obtained from a linear electron accelerator. Transient species formed by pulse radiolysis were detected by an optical absorption method. An aerated aqueous solution of KSCN $\left(1 \times 10^{-2} \mathrm{M}\right)$ was used to determine the dose delivered per pulse, monitoring the transient $(\mathrm{SCN})_{2}{ }^{--}$at $475 \mathrm{~nm}$, using $G \varepsilon(475 \mathrm{~nm})=2.59 \times 10^{-4} \mathrm{~m}^{2} \mathrm{~J}^{-1}$. Here, $G$ denotes the radiation chemical yield in $\mathrm{mol} \mathrm{J}^{-1}$ and $\varepsilon$ denotes the molar extinction coefficient in $\mathrm{m}^{2} \mathrm{~mol}^{-1}$. The dose per pulse was close to $10-12$ Gy per pulse $\left(1 \mathrm{~Gy}=1 \mathrm{~J} \mathrm{~kg}^{-1}\right)$. Radiolysis of $\mathrm{N}_{2}$-saturated neutral aqueous solution leads to the radiolysis of water, as given in eqn (3).

$$
\mathrm{H}_{2} \mathrm{O} \rightarrow \mathrm{H}^{\bullet}, \mathrm{OH}^{\bullet}, \mathrm{e}_{\mathrm{aq}}{ }^{-}, \mathrm{H}_{2}, \mathrm{H}_{2} \mathrm{O}_{2}, \mathrm{H}_{3} \mathrm{O}^{+}
$$

In studies, the ability of ND particles to scavenge $\mathrm{e}_{\mathrm{aq}}{ }^{-}$ was investigated by using different concentrations of ND in de-mineralized water, and compared with de-mineralized water without any nanomaterial added to it.

\subsection{Hydroxyl radical scavenging studies}

The scavenging activity of the nanomaterials (ND and ceria) was evaluated by performing competition kinetics using MG (malachite green) as the reference solute. Hydroxyl $\left(\mathrm{OH}^{\bullet}\right)$ radicals are generated by the Fenton reaction, where $\mathrm{Fe}^{2+}$ ions are oxidized by hydrogen peroxide as shown in eqn (4).

$$
\mathrm{Fe}^{2+}+\mathrm{H}_{2} \mathrm{O}_{2} \rightarrow \mathrm{Fe}^{3+}+\mathrm{OH}^{-}+\mathrm{OH}^{\bullet}
$$

MG is a triphenyl methane dye which is intense green in colour and has an absorption peak at $615 \mathrm{~nm}$. The $\mathrm{OH}^{\bullet}$ radicals formed react instantly with $\mathrm{MG}$ and oxidize it, as shown in eqn (5). This results in decolourization of the dye. The decay of absorbance at $615 \mathrm{~nm}$ was monitored in the absence and presence of different concentrations of nanomaterials (ND and ceria) as independent scavengers.

$$
\mathrm{MG}+\mathrm{OH}^{\bullet} \rightarrow \mathrm{MG}_{\mathrm{OX}}
$$

The final composition of the reaction mixture contains $12 \mu \mathrm{m}$ MG, $0.15 \mathrm{mM} \mathrm{FeSO}_{4}$ and varying concentrations of nanomaterial (ND or ceria). The reaction was initiated by adding $1 \mathrm{M}$ hydrogen peroxide. Absorbance-time plots in the absence and presence of different scavengers were fitted with first order kinetics. These studies were performed using a UV-VIS spectrometer (JASCO V-630 spectrophotometer) in a quartz cuvette $(1 \mathrm{~cm} \times 1 \mathrm{~cm})$.

\section{Results and discussion}

\subsection{Studies on membrane morphology and topography}

The surface and cross-section morphologies of the membranes are shown in Fig. 1. All the membranes demonstrate the typical morphology observed in the films produced by the phase inversion technique, with a dense top layer supported by a finger-like structure. The top surface of the control Psf membrane

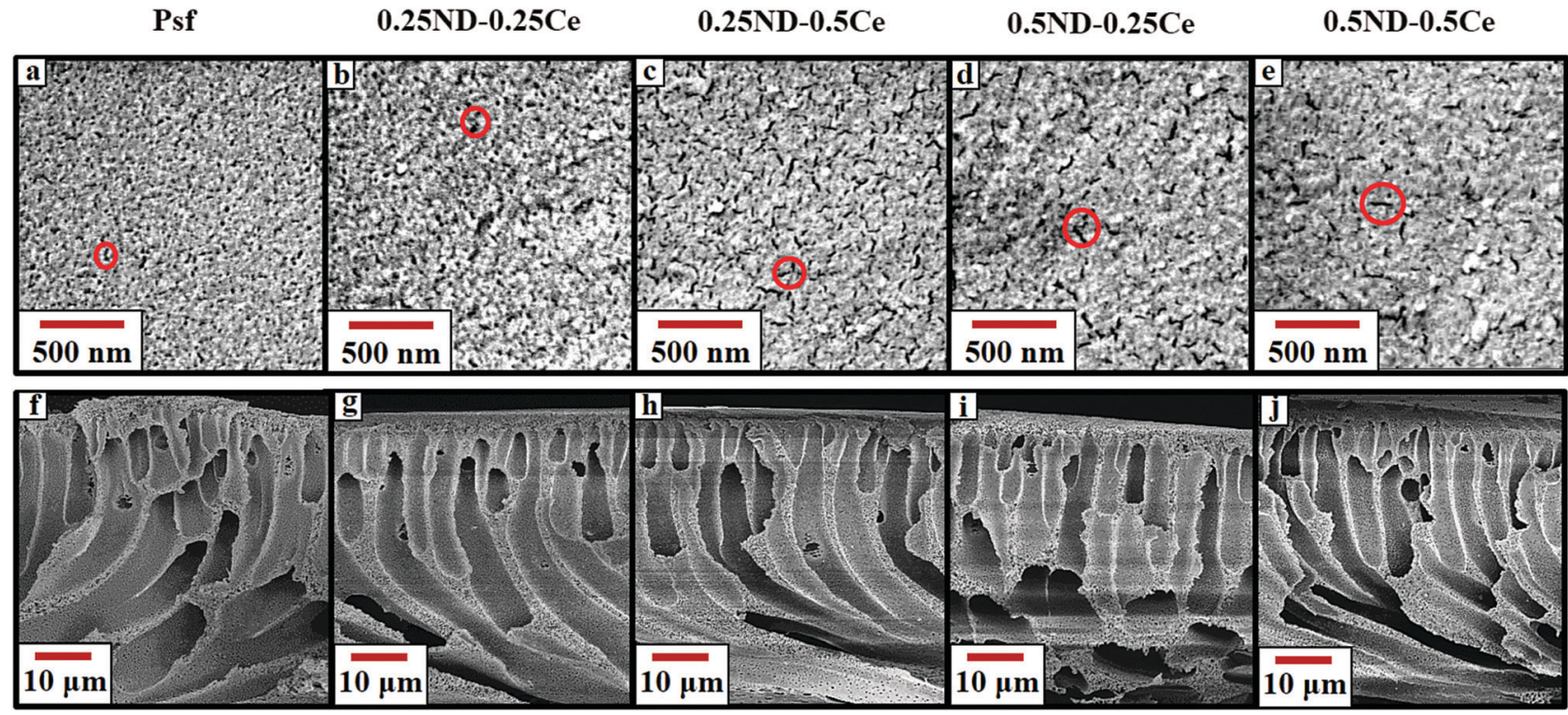

Fig. 1 FESEM images of the top surface (a-e) and cross-section ( $f-j)$ of the unirradiated Psf, $0.25 N D-0.25 C e, 0.25 N D-0.5 C e, 0.5 N D-0.25 C e$, and $0.5 \mathrm{ND}-0.5 \mathrm{Ce}$ membranes, respectively. 
is comparatively dense, while the membranes impregnated with ceria and ND nanoparticles have more free volume (shown in Fig. 1(a)-(e)). The free volume of the membrane represents pore channels that assist in enhancing the permeability of the membrane. ${ }^{37}$ During phase inversion, the addition of nanoparticles (ND and ceria) delays the exchange of solvent and nonsolvent due to increased viscosity of the casting solution, resulting in a wide finger-like structure. ${ }^{38,39}$ The hydrophilic hydroxyl and carboxyl functional groups attached to ND (shown in the ESI, $\dagger$ Fig. S3 and S4) attract water molecules, which increases the pore density of the membranes, as shown in Fig. $2 .^{40}$ The surface and cross-section morphologies (Fig. 1) show that by impregnating ND and ceria nanoparticles into the Psf host matrix, the free volume of the membrane increases due to the increased pore density (shown in Fig. 2), while pore size is not affected by the impregnation of nanoparticles (confirmed by the average pore size studies using a porometer provided later). The $\gamma$-radiation alters the morphology of the membranes due to simultaneous chain scissioning and cross-linking of the Psf chain. ${ }^{16,41}$ As a result, the control Psf membrane showed lower pore density, but increased pore size. However, the presence of ceria and ND protects the Psf matrix and prevents, to a reasonable extent, the onset of any deteriorating effects in the porous morphology. Therefore, the pore density and average pore size of the hybrid membranes increases after irradiation, leading to enhancement of permeability and decline of solute rejection abilities (discussed later). However, the 0.5ND-0.5Ce hybrid membrane does not show much variation in the average pore size of the membrane matrix even after $1000 \mathrm{kGy}$ radiation dose, while the pore density increases. There is no observable change in the membrane cross-section morphology after irradiation, as compared to the unirradiated membrane (Fig. S5, ESI, $\dagger$ Section S3). The 0.5\% optimum loading of both ND and ceria results in strong interfacial interactions with the polymer matrix preventing $\gamma$-induced degradation, which leads to water permeability enhancement without much variation in solute rejection (discussed later). Energy dispersive spectrometry (EDS) mapping of the Psf-ceria composite is shown in Fig. S6 of the ESI, $\dagger$ showing a ceria signature in the composite. However, when several locations of the hybrid MMM were investigated with EDS, the ceria signature was not observed. This could be due to the hydroxyl functional groups present on the surface of ND, and ceria being hydrophobic, which leads to preferential migration of ND to the top surface of the composite membrane during synthesis through the phase inversion technique, which is an important observation.

The average pore size of the unirradiated membranes obtained by porometry is found to be in the range of $0.08-0.1 \mu \mathrm{m}$ (Fig. S7, ESI, $\dagger$ Section S4) for all the unirradiated membranes (control Psf and hybrid), which confirms that the nanoparticles do not affect the pore size of the membrane matrix. After a radiation dose of $1000 \mathrm{kGy}$, the average pore size increases to $0.13,0.26,0.31,0.23$, and $0.16 \mu \mathrm{m}$ for the control Psf, $0.25 \mathrm{ND}-0.25 \mathrm{Ce}, 0.25 \mathrm{ND}-0.5 \mathrm{Ce}$, $0.5 \mathrm{ND}-0.25 \mathrm{Ce}$, and $0.5 \mathrm{ND}-0.5 \mathrm{Ce}$ membranes, respectively (Fig. S8, ESI, $\dagger$ Section S4). The increase in pore size leads to a decline in solute rejection abilities (discussed later). It is important to note that the $0.5 \mathrm{ND}-0.5 \mathrm{Ce}$ hybrid membrane shows the least variation in pore size, and hence its solute rejection ability is not significantly affected.

Fig. 3 shows the membrane surface roughness obtained from AFM studies. The impregnation of nanomaterials (ND and ceria) slightly increased the surface roughness of the membranes $^{42}$ from 3.26 (control Psf membrane) to $3.62 \mathrm{~nm}$ (0.5ND-0.5Ce hybrid membrane). This is due to the enhanced porosity of the membrane, as observed in the FESEM images (Fig. 2). The pore size of the control Psf membrane increases after irradiation (Fig. 2(f)), leading to an increase in surface roughness with radiation dose. The surface roughness of hybrid membranes also increases with radiation dose due to increase in pore density (shown in Fig. 2(g)-(j)). However, up to a $1000 \mathrm{kGy}$ radiation dose, the increase in roughness for the $0.5 \mathrm{ND}-0.5 \mathrm{Ce}$ hybrid membrane is only $8.6 \%$, compared to the increase of $18.8 \%$ for the control Psf membrane. The increased surface roughness resulted in the increased transportation of solvent through the membrane, as observed in the pure water permeability values discussed in a later section.

\subsection{Studies on physico-chemical properties of the membranes}

The hydrophilicity/hydrophobicity of the membrane surface was determined by water contact angle studies. As shown in Fig. 4, the water contact angle of the control Psf membrane is

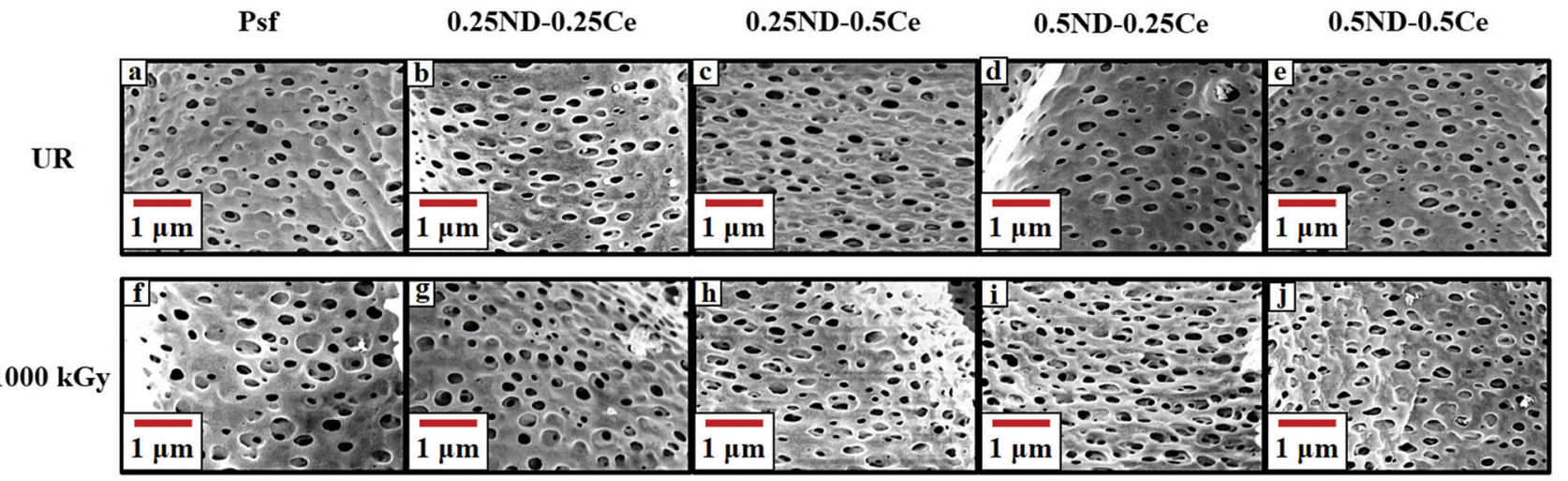

Fig. 2 FESEM images of the membrane surface of unirradiated (a-e) and $1000 \mathrm{kGy}$ irradiated (f-j) Psf, 0.25ND-0.25Ce, 0.25ND-0.5Ce, 0.5ND-0.25Ce, and 0.5ND-0.5Ce membranes, respectively. 


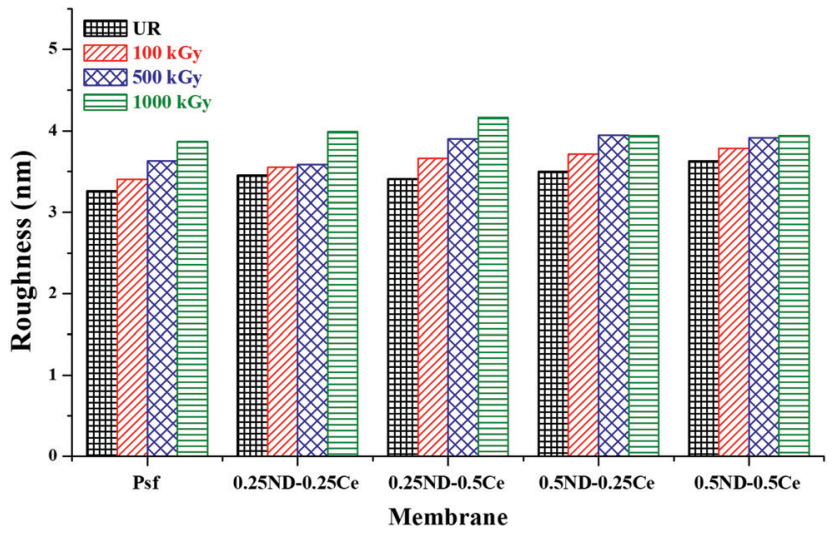

Fig. 3 Variation in root mean square surface roughness of the membrane with different ND and ceria loadings, at different radiation doses.

about $80^{\circ}$, which increases slightly to $85^{\circ}$ upon the addition of ceria and ND nanoparticles. The small increase in contact angle is due to the hydrophobic characteristics of ceria. ${ }^{43}$ The contact angle of each membrane decreases with the radiation dose due to increased surface roughness, as discussed in the previous section (Fig. 3). The decrease in contact angle is more pronounced in the hybrid membranes $\left(64.5,71.6,57\right.$, and $60.9^{\circ}$ for $0.25 \mathrm{ND}-0.25 \mathrm{Ce}, 0.25 \mathrm{ND}-0.5 \mathrm{Ce}, 0.5 \mathrm{ND}-0.25 \mathrm{Ce}$, and $0.5 \mathrm{ND}-$ $0.5 \mathrm{Ce}$, respectively, at $1000 \mathrm{kGy}$ radiation dose), compared to the control Psf membrane ( $73.6^{\circ}$ at $1000 \mathrm{kGy}$ radiation dose). This is due to the increased pore density (shown in Fig. $2(\mathrm{~g})-(\mathrm{j})$ ) with radiation, resulting in higher water uptake and enhancement of hydrophilicity. ${ }^{44}$ Radiation enhances the water permeability by enhancing hydrophilicity, while the nanoparticles stabilize the membrane matrix under radiation.

The weighted average molecular weight $\left(M_{\mathrm{w}}\right)$ of the membranes was determined by gel permeation chromatography (GPC), and cross-linking and chain-scissioning phenomena were observed during irradiation. ${ }^{45}$ As shown in Fig. $5, M_{\mathrm{w}}$ of the control Psf membrane slightly decreased after $100 \mathrm{kGy}$ irradiation, while that of the hybrid membranes increased. The variation in $M_{\mathrm{w}}$ indicates chain scissioning in the control

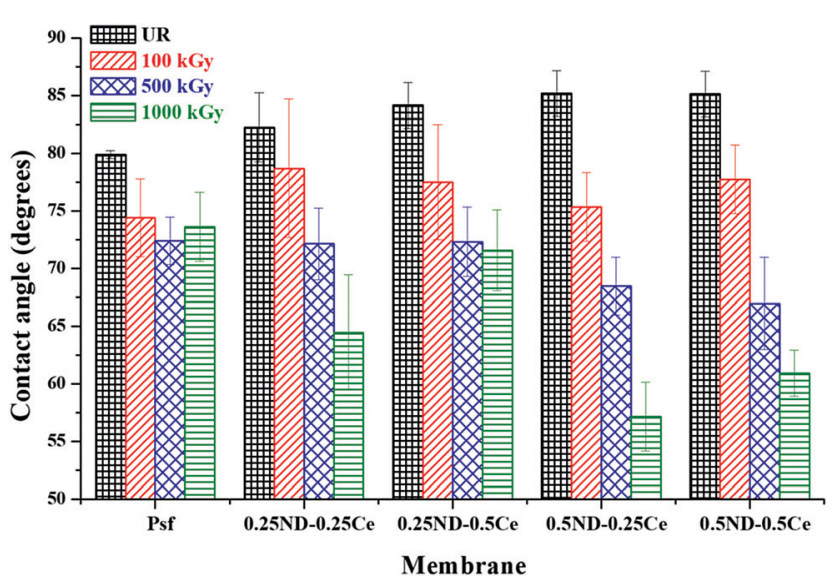

Fig. 4 Variation in membrane surface-water contact angle with different loadings of ND and ceria nanoparticles, at different radiation doses.
Psf and cross-linking in the hybrid membranes as the predominant phenomenon. For the control Psf membrane, the influence of the chain scissioning phenomenon increases with radiation dose, and therefore $M_{\mathrm{w}}$ decreases from $63241 \mathrm{Da}$ for unirradiated Psf (Psf-UR) to 34954 Da for Psf irradiated up to 1000 kGy (Psf-1000 kGy). On the other hand, the hybrid membranes exhibit cross-linking phenomenon up to a radiation dose of $500 \mathrm{kGy}$. Above $500 \mathrm{kGy}$ radiation dose, chain-scissioning predominates and consequently $M_{\mathrm{w}}$ starts to decrease. The 0.5ND-0.5Ce hybrid membrane does not show a significant difference in $M_{\mathrm{w}}$, even up to a radiation dose of $1000 \mathrm{kGy}$. The results confirm the enhanced stability of the Psf membrane matrix up to $1000 \mathrm{kGy}$ due to the presence of $0.5 \% \mathrm{ND}$ and $0.5 \%$ ceria. This stability against $\gamma$-radiation can be attributed to the free radical scavenging properties of ceria and ND (discussed later).

\subsection{Studies on the oxidative degradation of the membranes}

The thermal oxidative stability of the membranes was investigated by differential scanning calorimetry (DSC) studies. Fig. 6(a) shows the DSC thermograms of the unirradiated membranes, where the effect of ND and ceria loading on the thermal oxidative degradation of the membrane matrix can be observed. The DSC thermogram of the control Psf membrane shows three exotherms with increasing temperature peaks at $\sim 430, \sim 530$, and $\sim 590{ }^{\circ} \mathrm{C}$. Since Psf is a polymeric network, it undergoes crystallization/partial crystallization with heating (which also gives an exothermic DSC trace). Reinforcement of Psf with ND and ceria nanoparticles (0.25-0.5 wt\%) does not show any observable effects on the peak temperature of the first exotherm $\left(\sim 430^{\circ} \mathrm{C}\right)$. While the other four membrane samples show a single peak, the $0.5 \mathrm{ND}-0.5 \mathrm{Ce}$ membrane shows two peaks before the onset of the second exotherm, indicating that higher loading of ND and ceria affects the thermal response of Psf towards this exothermic phenomenon. The stage 2 exotherm also remains almost invariant in terms of peak temperature $\left(\sim 525\right.$ to $\left.529{ }^{\circ} \mathrm{C}\right)$. The stage 3 exotherm shows distinct behavior with ND and ceria loading, wherein the peak at $\sim 589{ }^{\circ} \mathrm{C}$ for the control Psf sharply decreases by $\sim 15{ }^{\circ} \mathrm{C}$ for

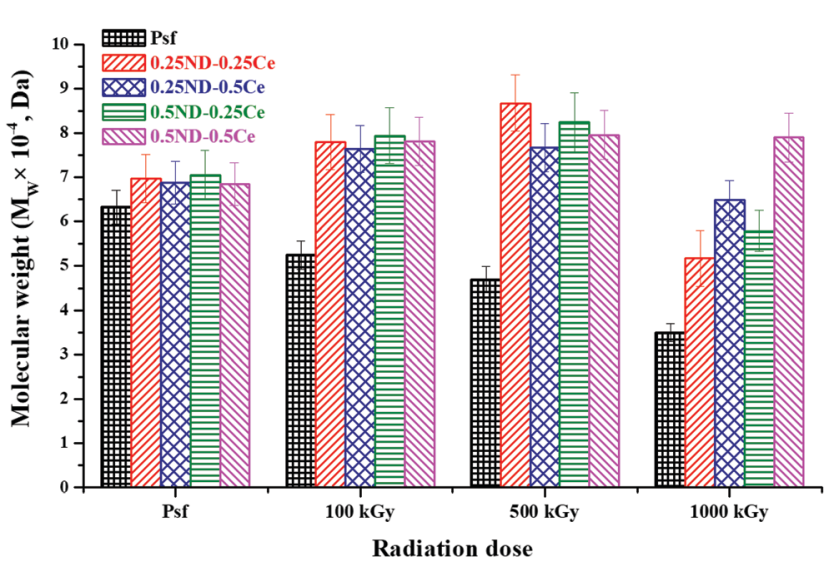

Fig. 5 Change in weighted average molecular weight of the membranes with different radiation doses. 

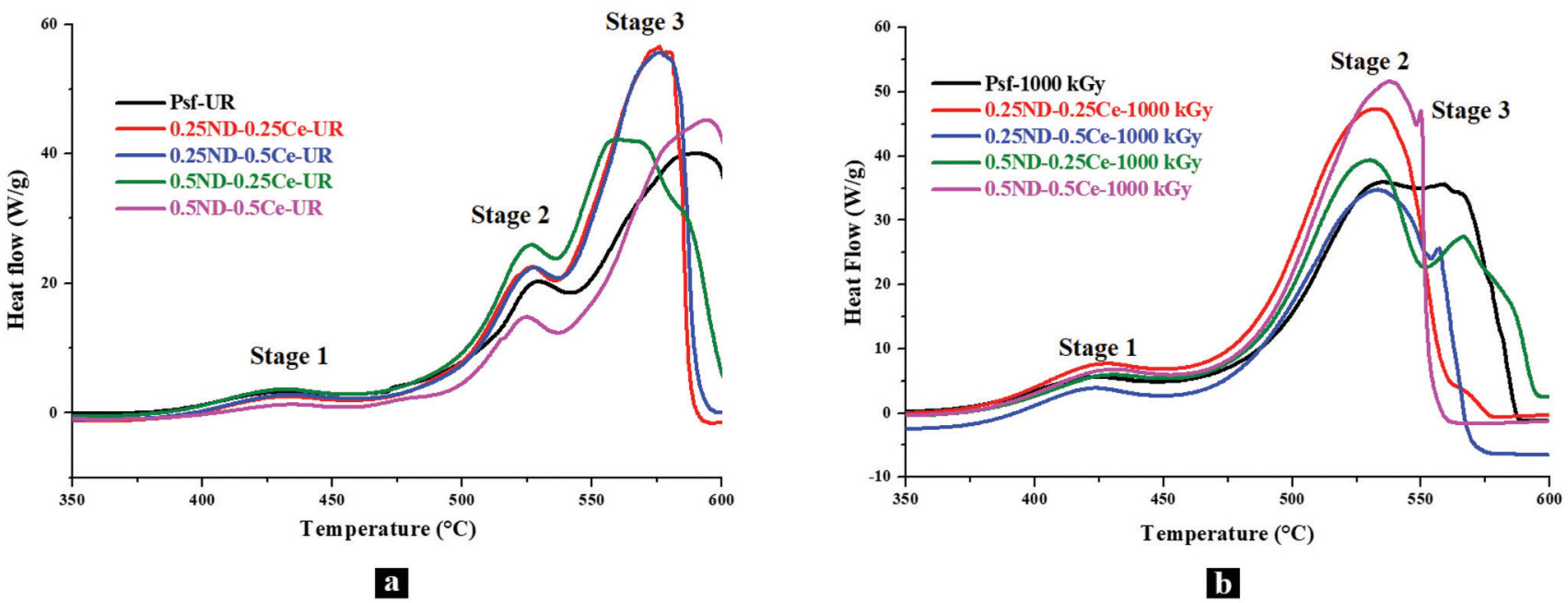

Fig. 6 DSC thermograms of the membranes with different loadings of ND and ceria; (a) unirradiated and (b) 1000 kGy dose irradiated membranes.

the $0.25 \mathrm{ND}-0.25 \mathrm{Ce}$ membrane sample, indicating that the composite membrane has reduced thermo-oxidative stability as compared to the control Psf membrane. Also, the onset of the exotherm is shifted to lower temperatures, further corroborating the inference of the composite's lower thermal stability. Decomposition is apparently completed before $600{ }^{\circ} \mathrm{C}$ for both the $0.25 \mathrm{ND}-0.25 \mathrm{Ce}$ and $0.25 \mathrm{ND}-0.5 \mathrm{Ce}$ membrane samples, and is incomplete for the control Psf membrane sample up to $600{ }^{\circ} \mathrm{C}$. Further reinforcement of nanoparticles shows a reduction in the peak temperature to $\sim 565{ }^{\circ} \mathrm{C}$ (reduced by $\sim 10{ }^{\circ} \mathrm{C}$ ) for the $0.5 \mathrm{ND}-0.25 \mathrm{Ce}$ membrane, which is in line with the observed trend. However, at the same time, the exotherm is clearly broadened, with an additional high temperature exotherm overlapping with the $565{ }^{\circ} \mathrm{C}$ peak exotherm, which can be seen from the shoulder-type peak. This suggests that ND addition has a more distinct effect on thermo-oxidative stability than ceria reinforcement. Very interestingly, the 0.5ND-0.5Ce membrane sample shows an anomalous increase in the peak decomposition temperature (stage 3), which indicates increased thermal stability. Also, decomposition is not completed until $600{ }^{\circ} \mathrm{C}$ (similar to the control Psf). The findings show distinctly higher thermal stability of this composite membrane, while those with lower loadings $(0.25 \mathrm{ND}-0.25 \mathrm{Ce}$, $0.25 \mathrm{ND}-0.5 \mathrm{Ce}$ and $0.5 \mathrm{ND}-0.25 \mathrm{Ce}$ ) show the opposite trend. Regarding the irradiated samples, a decrease in the peak temperature of stage 1 by $5-6{ }^{\circ} \mathrm{C}$ for the control Psf membrane indicates radiation induced degradation in the Psf matrix, which leads to reduced stability of the polymer membrane around $430{ }^{\circ} \mathrm{C}$. An increase in the stage 1 peak temperature $\left(430{ }^{\circ} \mathrm{C}\right)$ of the irradiated composite membranes with higher ND loading (0.5ND-0.25Ce \& $0.5 \mathrm{ND}-0.5 \mathrm{Ce}$ ) again indicates that ND does have a stabilizing effect towards the thermal response. Stage 2 and 3 of the irradiated Psf are highly overlapped. Interestingly, the stage 2 peak shows an upward shift, while that of stage 3 shows a significant downward shift in temperature. Since it is the control Psf, these effects are manifestations of irradiation weakening the polymer network. In all the irradiated samples, stage 2 is much more intense than stage 3 , while the reverse is observed in all the unirradiated samples. Due to the radiation induced damage of the membrane matrix by chain scissioning and cross-linking, the range of order in the Psf chain is altered, which is clearly observed in Fig. 6(b). Psf-1000 kGy shows a broad peak in the range of 534 to $556{ }^{\circ} \mathrm{C}$, which indicates that diverse sizes of Psf chains occur due to chain scissioning and cross-linking phenomena (as observed in GPC analysis, shown in Fig. 5). Table 2 shows only a small effect for higher order chains in stage 3 for the hybrid membranes due to chain scissioning at $1000 \mathrm{kGy}$ (as observed in GPC analysis, Fig. 5). It is clear from the comparison of thermograms of the unirradiated membrane samples with those of the irradiated ones that the Psf network is significantly affected by irradiation compared to the composite membranes, with the 0.5ND-0.5Ce membrane offering enhanced stability against thermo-oxidative degradation.

\subsection{Studies on mechanical properties of the membranes}

The mechanical properties of the membranes were investigated in terms of tensile strength (TS) and percentage elongation $(\% E)$ at maximum force, as shown in Fig. 7. The TS and $\% E$ of the control Psf membrane are $3.07 \mathrm{MPa}$ and $14.2 \%$, respectively. By impregnation of ND and ceria, the mechanical strength of all the hybrid membranes is increased, with TS and $\% E$ of $4.17 \mathrm{MPa}$ and $19.2 \%$, respectively, for the membrane

Table 2 Three-stage oxidative degradation peak temperatures of the unirradiated and 1000 kGy irradiated membranes

\begin{tabular}{|c|c|c|c|c|c|c|}
\hline \multirow[b]{3}{*}{ Membrane } & \multicolumn{6}{|c|}{ Peak temperature $\left({ }^{\circ} \mathrm{C}\right)$} \\
\hline & \multicolumn{3}{|c|}{ Unirradiated } & \multicolumn{3}{|c|}{$1000 \mathrm{kGy}$ irradiated } \\
\hline & Stage 1 & Stage 2 & Stage 3 & Stage 1 & Stage 2 & Stage 3 \\
\hline Psf & 430 & 529 & 589 & 424 & 534 & 556 \\
\hline $0.25 \mathrm{ND}-0.25 \mathrm{Ce}$ & 430 & 526 & 575 & 425 & 532 & 534 \\
\hline $0.25 \mathrm{ND}-0.5 \mathrm{Ce}$ & 430 & 528 & 576 & 424 & 533 & 557 \\
\hline $0.5 \mathrm{ND}-0.25 \mathrm{Ce}$ & 430 & 526 & 564 & 430 & 530 & 566 \\
\hline $0.5 \mathrm{ND}-0.5 \mathrm{Ce}$ & 430 & 525 & 594 & 430 & 538 & 550 \\
\hline
\end{tabular}



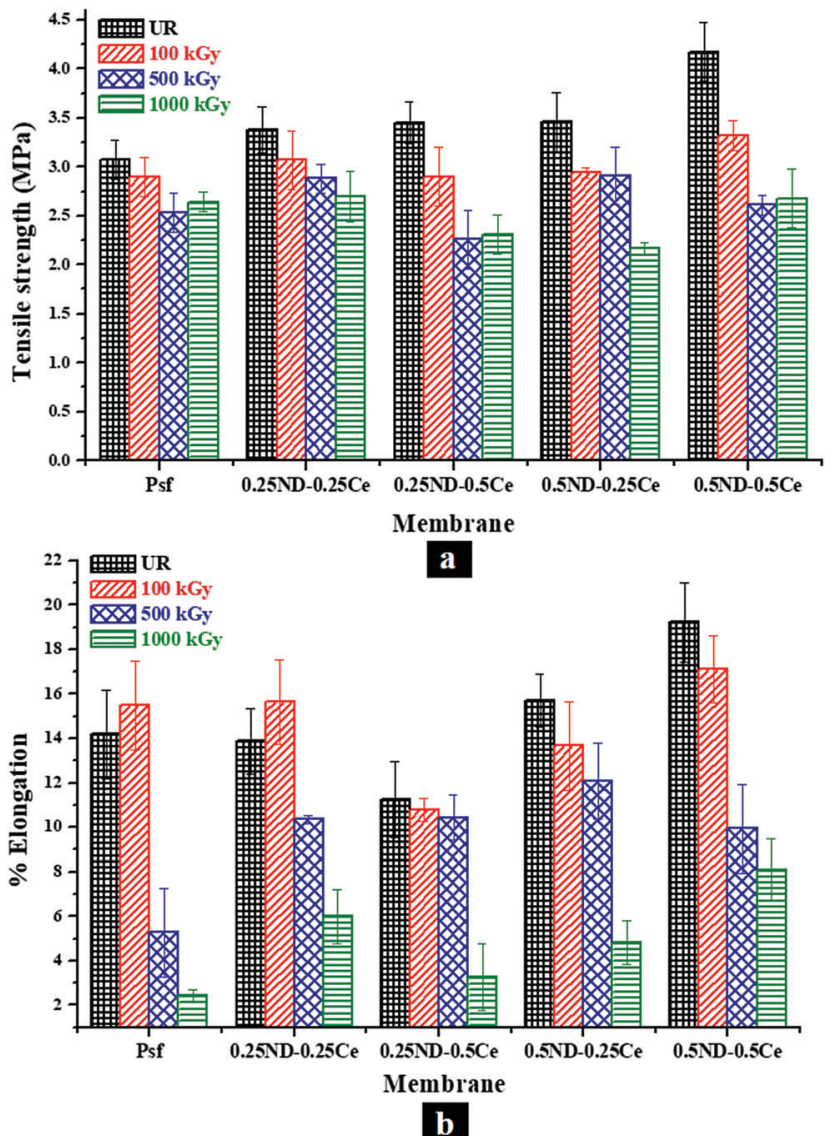

Fig. 7 Mechanical properties of the membranes: variation in (a) tensile strength and (b) percentage elongation at maximum force, with different loadings of ND and ceria in the membrane matrix at different radiation doses.

with $0.5 \%$ each of ND and ceria. ${ }^{46}$ The mechanical properties of the membranes mainly depend on two factors. One is the size of nanoparticles, which is crucial for interfacial interactions between the nanoparticles and Psf. The average size of the ND nanoparticles is about $5 \mathrm{~nm}$ (Fig. S1, ESI $\dagger$ ) and that of ceria is about $12 \mathrm{~nm}$ (Fig. S2, ESI $\dagger$ ), which leads to a high surface to volume ratio of nanoparticles, and hence an excellent interfacial area for enhanced interaction between the polymer and nanomaterials. Another factor is the distribution of nanoparticles in the membrane matrix. The uniform distribution of nanoparticles provides strong interactions, while agglomeration reduces the number density of the particles, resulting in reduced interaction. $0.5 \%$ loading of both ND and ceria in the Psf host matrix was found to be the optimum in terms of uniform distribution and strong interactions, thus offering enhanced mechanical properties. ${ }^{47}$ After $100 \mathrm{kGy}$ of irradiation, the control Psf membrane starts losing its mechanical strength due to chain scissioning, as observed in the GPC analysis shown in Fig. $5 .{ }^{48}$ On the other hand, the value of $\% E$ is slightly increased because the chain scissioning leads to increased flexibility of the Psf chain. A similar observation is made for the $0.25 \mathrm{ND}-0.25 \mathrm{Ce}$ membrane, as the small loading of nanomaterials does not affect significantly the rigidity of the Psf matrix. On the other hand, higher loading of nanomaterials introduces rigidity in the Psf matrix. A further increase in the radiation dose leads to chain scissioning of the Psf chains, as a result of which the mechanical properties deteriorate. The increase in pore density of the hybrid membranes (as observed in the pore distribution images, Fig. 2) due to radiation also results in reduced TS and $\% E$ with dose. ${ }^{49}$ The reduction in $\% E$ of the hybrid membranes is less than that of the control Psf membrane for a radiation dose up to $1000 \mathrm{kGy}$, as shown in Fig. 7(b). The results indicate that the mechanical properties of the hybrid membranes are restored even after $1000 \mathrm{kGy}$ radiation dose. The $0.25 \mathrm{ND}-0.25 \mathrm{Ce}$ and $0.5 \mathrm{ND}-0.5 \mathrm{Ce}$ hybrid membranes are found to be the most stable in the radiation environment in terms of their mechanical properties.

\subsection{Studies on performance of membranes}

Fig. 8 shows the membrane performance based on pure water permeability and solute rejection attributes of the membranes for PEO-100 kDa. The permeability offered by the control Psf membrane was found to be about $156 \mathrm{~L} \mathrm{~m}^{-2} \mathrm{~h}^{-1}$ with $94.6 \%$ rejection, while all the hybrid membranes exhibited improved permeability and rejection. The inherent trade-off found in any polymeric membrane system is observed to be reduced to a
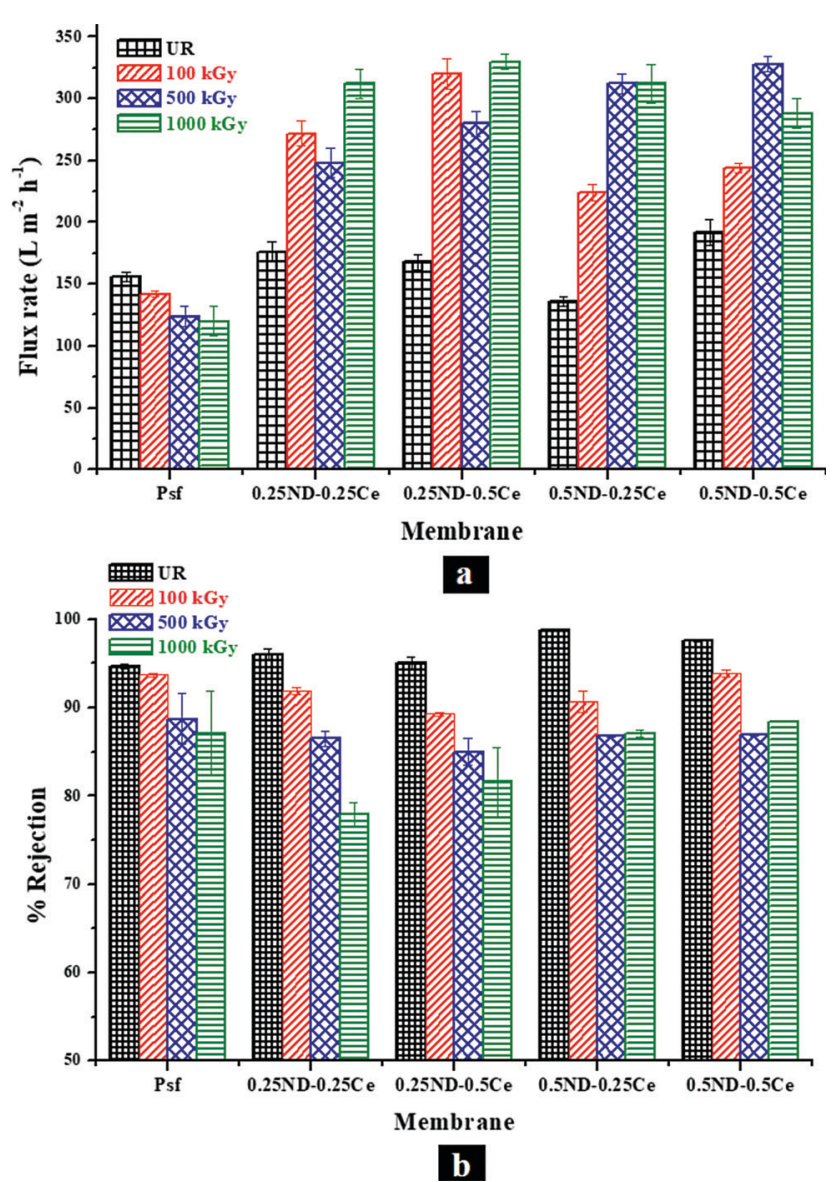

Fig. 8 Variation in (a) pure water permeability and (b) percentage rejection of PEO (100 kDa), with different loadings of ND and ceria in the membrane matrix at different radiation doses. 
reasonable extent in the hybrid membranes. The permeability of the $0.5 \mathrm{ND}-0.5 \mathrm{Ce}$ membrane increased up to $192 \mathrm{~L} \mathrm{~m}^{-2} \mathrm{~h}^{-1}$ with $97.6 \%$ solute rejection. The performance is enhanced due to the increased pore density of the membrane, as shown in the FESEM image in Fig. 2(e). ${ }^{50}$ This indicates that the presence of ND and ceria nanoparticles could create additional pathways for water flow, without increasing the pore size. The enhanced surface roughness (Fig. 3) and hydrophilic groups present on the ND surface (Fig. S3 and S4, ESI $\dagger$ ) also contribute to the increase in permeability. Hence, the solute rejection, as well as the solvent flux, increases. Upon exposure to radiation, the permeability of the control Psf membrane decreased to $120 \mathrm{~L} \mathrm{~m}^{-2} \mathrm{~h}^{-1}$ and the rejection rate to $87 \%$, which could be due to the increase in pore size and reduced pore density of the membrane, as can be seen in the FESEM image in Fig. 2(f). This is due to degradation of the Psf matrix by chain scissioning in the $\gamma$-radiation environment, as confirmed by the GPC analysis shown in Fig. 5 . On the other hand, due to the increased pore density of the hybrid membranes in the radiation environment (FESEM images, Fig. 2), the permeability is enhanced with a slight reduction in the rejection attributes. At $1000 \mathrm{kGy}$ radiation dose, the $0.5 \mathrm{ND}-$ $0.5 \mathrm{Ce}$ hybrid membrane shows permeability of $288 \mathrm{~L} \mathrm{~m}^{-2} \mathrm{~h}^{-1}$ with $88.5 \%$ rejection. This ascertains the resistance of hybrid membranes against chain scissioning and cross-linking phenomena, as also confirmed by the consistent molecular weight of the membranes (GPC analysis, Fig. 5). These results clearly confirm the improved performance of the membranes and their stability in the radiation environment with the impregnation of ND and ceria nanoparticles.

\subsection{Free radical scavenging activity of ND and ceria nanoparticles}

3.6.1 $\mathrm{e}_{\mathrm{aq}}{ }^{-}$scavenging capability of ND particles. The characteristic absorption spectrum of $\mathrm{e}_{\mathrm{aq}}{ }^{-}$has a broad, structureless band with a maximum around $700 \mathrm{~nm}$ in an aqueous system. In general, the reactivity of $\mathrm{e}_{\mathrm{aq}}{ }^{-}$is investigated by monitoring the time absorption plot at $700 \mathrm{~nm}$ in the presence of different concentrations of ND particles. Scavenging of $\mathrm{e}_{\mathrm{aq}}{ }^{-}$radicals by ND particles was confirmed by monitoring their reaction with varying concentrations of ND particles (Fig. 9). The results showed that increasing the ND concentration leads to the rapid decay of hydrated electrons, which confirms that ND is responsible for scavenging the most reactive radiolysed product $\left(\mathrm{e}_{\mathrm{aq}}{ }^{-}\right)$of water.

3.6.2 Hydroxyl radical scavenging capability of ND particles. The maximum absorption peak of $\mathrm{MG}$ is at $\sim 615 \mathrm{~nm}$. To understand the participation of ND particles in the reaction, the oxidation of $\mathrm{MG}$ was performed by $\mathrm{OH}^{\bullet}$ radicals in the presence of different concentrations of ND particles. Fig. 10 shows the degradation of MG in the presence of different concentrations of ND. As shown in the inset of Fig. 10, with an increase in the concentration of $\mathrm{ND}$, the degradation rate of MG decreases. This indicates scavenging of $\mathrm{OH}^{\bullet}$ radicals by ND particles. The $\mathrm{OH}^{\bullet}$ radical scavenging phenomenon of ND particles is expressed in eqn (6).

$$
\mathrm{ND}+\mathrm{OH}^{\bullet}+\mathrm{H}^{+} \rightarrow \mathrm{ND}_{\mathrm{OX}}+\mathrm{H}_{2} \mathrm{O}
$$

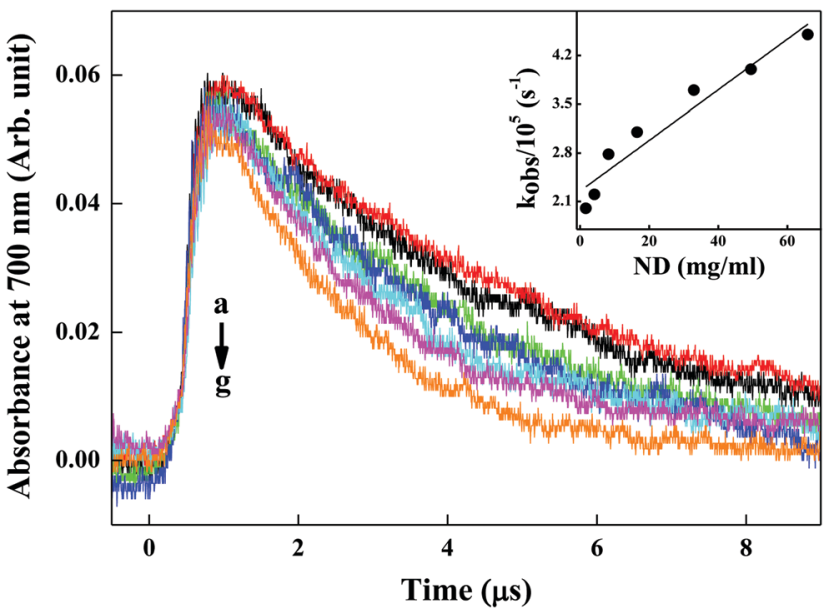

Fig. 9 Absorption-time plot of hydrated electrons of water at $700 \mathrm{~nm}$ in the presence of varying concentrations of ND particles suspended in aqueous solution containing $1 \mathrm{Mt}$-butanol at $\mathrm{pH} 7$ under $\mathrm{N}_{2}$ saturated conditions. Here, the plots correspond to ND concentrations of (a) $1.65 \mu \mathrm{g} \mathrm{m}^{-1}$, (b) $4.12 \mu \mathrm{g} \mathrm{ml}^{-1}$, (c) $8.25 \mu \mathrm{g} \mathrm{ml} \mathrm{m}^{-1}$, (d) $16.5 \mu \mathrm{g} \mathrm{ml} \mathrm{m}^{-1}$, (e) $33 \mu \mathrm{g} \mathrm{ml}^{-1}$, (f) $49.5 \mu \mathrm{g} \mathrm{ml}^{-1}$, (g) $66 \mu \mathrm{g} \mathrm{ml}^{-1}$. Inset shows the plot of the observed rate of hydrated electrons as a function of ND particle concentration at $\mathrm{pH} 7$.

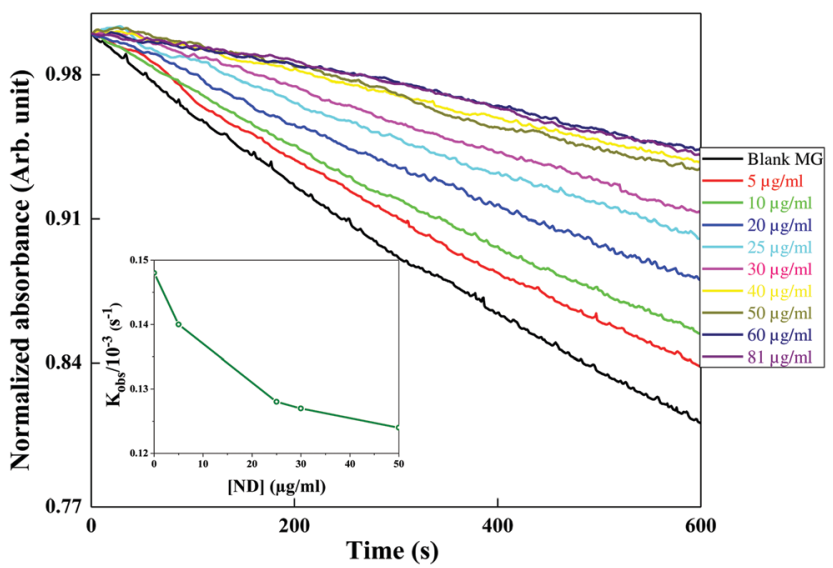

Fig. 10 Hydroxyl radical scavenging by ND particles. Inset shows the inhibition of absorbance of $\mathrm{MG}$ due to $\mathrm{OH}^{\bullet}$ radical induced degradation in the presence of different concentrations of ND particles $\left(5-81 \mu \mathrm{g} \mathrm{ml}^{-1}\right)$.

The decrease in degradation rate of $\mathrm{MG}\left(k_{\mathrm{obs}}\right)$ with the concentration of ND confirms the increased $\mathrm{OH}^{\bullet}$ radical scavenging activity of ND.

3.6.3 Hydroxyl radical scavenging capability of ceria nanoparticles. To understand the participation of ceria nanoparticles in the reaction, the oxidation of MG was performed by $\mathrm{OH}^{\bullet}$ radicals in the presence of different concentrations of ceria nanoparticles. Fig. 11 shows the degradation of MG in the presence of different concentrations of ceria. As shown in the inset of Fig. 11, with an increase in the concentration of ceria, the degradation rate of MG decreases. This indicates scavenging of $\mathrm{OH}^{\bullet}$ radicals by ceria nanoparticles. The $\mathrm{OH}^{\bullet}$ radical scavenging phenomenon of ceria nanoparticles is expressed in eqn (7).

$$
\mathrm{Ce}^{3+}+\mathrm{OH}^{\bullet}+\mathrm{H}^{+} \rightarrow \mathrm{Ce}^{4+}+\mathrm{H}_{2} \mathrm{O}
$$




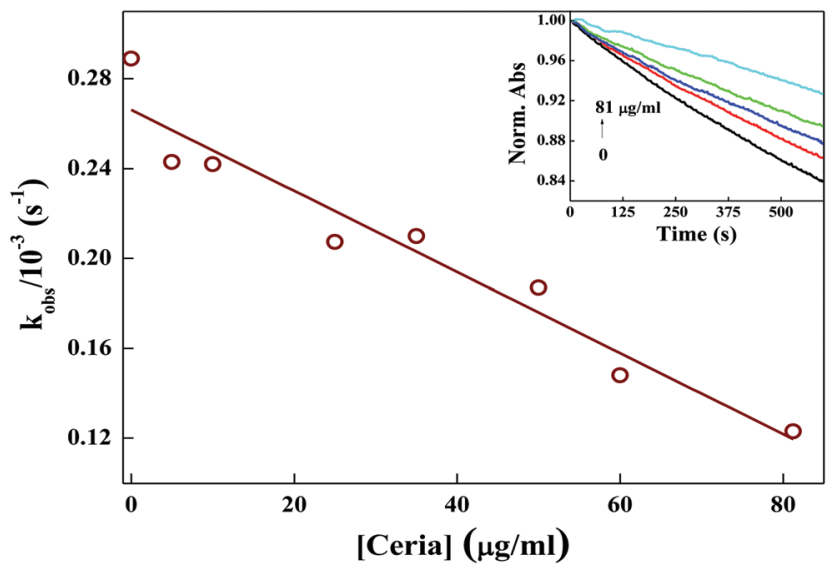

Fig. 11 Hydroxyl radical scavenging by ceria nanoparticles. Inset shows the inhibition of absorbance of $\mathrm{MG}$ due to $\mathrm{OH}^{\bullet}$ radical induced degradation in the presence of different concentrations of ceria nanoparticles $\left(5-81 \mu \mathrm{gll}^{-1}\right)$.

The decrease in degradation rate of MG $\left(k_{\mathrm{obs}}\right)$ with the concentration of ceria confirms the increased $\mathrm{OH}^{\bullet}$ radical scavenging activity of ceria.

\section{Conclusions}

With the objective of expanding the applications of polymeric membranes in $\gamma$-radiation environments, Psf-(ND $+\mathrm{Ce})$ hybrid membranes were synthesized by impregnation of nanodiamond (ND) and cerium oxide nanoparticles (ceria) into the Psf host matrix. Ceria protects the Psf membrane matrix by scavenging secondary free radicals generated due to the $\gamma$-radiolysis of water, while ND offers strength and enhances the overall lifetime of the membrane in the $\gamma$-radiation environment. These Psf-(ND + Ce) hybrid membranes are found to offer increased free volume, compared to the control Psf membranes, due to the enhanced pore density. This results in increased surface roughness and permeability of the hybrid membranes, without compromise in the selectivity. The mechanical properties of the hybrid membranes are also improved in terms of tensile strength and percentage elongation. In addition, the loading of ND and ceria makes the Psf matrix stable against oxidative degradation at high temperatures in the radiation environment. All the Psf-(ND + Ce) hybrid membranes are found to be stable up to $500 \mathrm{kGy}$ radiation dose, while the $0.5 \mathrm{ND}-0.5 \mathrm{Ce}$ membrane is found to be stable up to $1000 \mathrm{kGy}$. The hybrid membrane with an optimum composition of $0.5 \mathrm{wt} \%$ of both ND and ceria is found to be $\sim 10$ times more radiation resistant than the control Psf membrane. The free radical scavenging studies undertaken here provide important and interesting insights into and evidence for the roles and mechanisms of ND and ceria nanoparticles in offering radiation resistant properties to hybrid membranes with synergy. The present study makes a classic beginning of the development of an important class of hybrid membranes with enhanced radiation stability.

\section{Conflicts of interest}

There are no conflicts to declare.

\section{Acknowledgements}

The authors would like to acknowledge Dr. V. Kumar, RTDD (BARC) for providing the gamma chamber facility for the irradiation of membranes; Dr. Chhavi Agarwal, RCD (BARC) for the porometry analysis; Mr. S. Kumar, MSD (BARC) for the FESEM analysis; Ms. Sharwari Ghodke, ICT (Mumbai) for the GPC analysis; Mr. N. Goswami and Mr. A. K. Singha, MDS (BARC) for the design and fabrication of the table top membrane casting machine and Mr. R. B. Bramhane and Mr. P. P. Surve, MDS (BARC) for the operation of the membrane casting machine.

\section{References}

1 B. Van der Bruggen, C. Vandecasteele, T. Van Gestel, W. Doyen and R. Leysen, A review of pressure-driven membrane processes in wastewater treatment and drinking water production, Environ. Prog., 2003, 22, 46-56.

2 J. Yin and B. Deng, Polymer-matrix nanocomposite membranes for water treatment, J. Membr. Sci., 2015, 479, 256-275.

3 Y. Wang, K. S. Chen, J. Mishler, S. C. Cho and X. C. Adroher, A review of polymer electrolyte membrane fuel cells: Technology, applications, and needs on fundamental research, Appl. Energy, 2011, 88, 981-1007.

4 W. J. Koros and G. Fleming, Membrane-based gas separation, J. Membr. Sci., 1993, 83, 1-80.

5 M. M. Amiji, Permeability and blood compatibility properties of chitosan-poly(ethylene oxide) blend membranes for haemodialysis, Biomaterials, 1995, 16, 593-599.

6 R. Boock, M. A. Rixman, H. Zhang, M. J. Estes and K. Lawrence, Polymer membranes for continuous analyte sensors, US Pat., 12/413166, 2009.

7 A. Salahi, A. Gheshlaghi, T. Mohammadi and S. S. Madaeni, Experimental performance evaluation of polymeric membranes for treatment of an industrial oily wastewater, Desalination, 2010, 262, 235-242.

8 J. Mulder, Basic principles of membrane technology, Springer Science \& Business Media, 2012.

9 K. L. Nash and G. J. Lumetta, Advanced separation techniques for nuclear fuel reprocessing and radioactive waste treatment, Elsevier, 2011.

10 A. Davis, Comparison of the thermal and thermo oxidative stability of polycarbonate, polyphenylene oxide, polysulphone and two polyarylates, Makromol. Chem., 1970, 132, 23-33.

11 H. Vogel, Polyarylsulfones, synthesis and properties, J. Polym. Sci., Part A-1: Polym. Chem., 1970, 8, 2035-2047.

$12 \mathrm{~J}$. Brown and J. O'Donnell, The radiation stability of an aromatic polysulfone, J. Polym. Sci., Part B: Polym. Lett., 1970, 8, 121-126. 
13 M. Khayet, Treatment of radioactive wastewater solutions by direct contact membrane distillation using surface modified membranes, Desalination, 2013, 321, 60-66.

14 D. R. Tenney, W. S. Slemp, E. R. Long Jr and G. F. Sykes, Advanced materials for space, Large Space Systems Technology-1979, 1980.

15 K. Murakami and H. Kudo, Gamma-rays irradiation effects on polysulfone at high temperature, Nucl. Instrum. Methods Phys. Res., Sect. B, 2007, 265, 125-129.

$16 \mathrm{~J}$. Brown and J. O'Donnell, Effects of gamma radiation on two aromatic polysulfones, J. Appl. Polym. Sci., 1975, 19, 405-417.

17 A. H. Samuel and J. L. Magee, Theory of radiation chemistry. II. Track effects in radiolysis of water, J. Chem. Phys., 1953, 21, 1080-1087.

18 A. S. Edelstein and R. Cammaratra, Nanomaterials: synthesis, properties and applications, CRC Press, 1998.

19 A. A. Balandin, Thermal properties of graphene and nanostructured carbon materials, Nat. Mater., 2011, 10, 569.

20 A. C. Neto, F. Guinea, N. M. Peres, K. S. Novoselov and A. K. Geim, The electronic properties of graphene, Rev. Mod. Phys., 2009, 81, 109.

21 X. Zhao, Q. Zhang, D. Chen and P. Lu, Enhanced mechanical properties of graphene-based poly(vinyl alcohol) composites, Macromolecules, 2010, 43, 2357-2363.

22 S. K. Das, A. Bedar, A. Kannan and K. Jasuja, Aqueous dispersions of few-layer-thick chemically modified magnesium diboride nanosheets by ultrasonication assisted exfoliation, Sci. Rep., 2015, 5, 10522.

23 R. A. Damodar, S.-J. You and H.-H. Chou, Study the self cleaning, antibacterial and photocatalytic properties of $\mathrm{TiO}_{2}$ entrapped PVDF membranes, J. Hazard. Mater., 2009, 172, 1321-1328.

24 Y. Yang and P. Wang, Preparation and characterizationsof a new PS/TiO 2 hybrid membranes by sol-gel process, Polymer, 2006, 47, 2683-2688.

25 Z. Yu, X. Liu, F. Zhao, X. Liang and Y. Tian, Fabrication of a low-cost nano-SiO $\mathrm{S}_{2} \mathrm{PVC}$ composite ultrafiltration membrane and its antifouling performance, J. Appl. Polym. Sci., 2015, 132, 41267.

26 S. Liang, K. Xiao, Y. Mo and X. Huang, A novel ZnO nanoparticle blended polyvinylidene fluoride membrane for anti-irreversible fouling, J. Membr. Sci., 2012, 394-395, 184-192.

27 J.-H. Li, X.-S. Shao, Q. Zhou, M.-Z. Li and Q.-Q. Zhang, The double effects of silver nanoparticles on the PVDF membrane: Surface hydrophilicity and antifouling performance, Appl. Surf. Sci., 2013, 265, 663-670.

28 M. Homayoonfal, M. R. Mehrnia, M. Shariaty-Niassar, A. Akbari, A. F. Ismail and T. Matsuura, A comparison between blending and surface deposition methods for the preparation of iron oxide/polysulfone nanocomposite membranes, Desalination, 2014, 354, 125-142.

29 Z. Xu, J. Zhang, M. Shan, Y. Li, B. Li, J. Niu, B. Zhou and $\mathrm{X}$. Qian, Organosilane-functionalized graphene oxide for enhanced antifouling and mechanical properties of polyvinylidene fluoride ultrafiltration membranes, J. Membr. Sci., 2014, 458, 1-13.

30 S. Zinadini, A. A. Zinatizadeh, M. Rahimi, V. Vatanpour and H. Zangeneh, Preparation of a novel antifouling mixed matrix PES membrane by embedding graphene oxide nanoplates, J. Membr. Sci., 2014, 453, 292-301.

31 V. N. Mochalin, O. Shenderova, D. Ho and Y. Gogotsi, The properties and applications of nanodiamonds, Nat. Nanotechnol., 2012, 7, 11.

32 H. Wu, L. Shabala, S. Shabala and J. P. Giraldo, Hydroxyl radical scavenging by cerium oxide nanoparticles improves Arabidopsis salinity tolerance by enhancing leaf mesophyll potassium retention, Environ. Sci.: Nano, 2018, 5, 1567-1583.

33 J. Colon, L. Herrera, J. Smith, S. Patil, C. Komanski, P. Kupelian, S. Seal, D. W. Jenkins and C. H. Baker, Protection from radiation-induced pneumonitis using cerium oxide nanoparticles, Nanomedicine, 2009, 5, 225-231.

34 W. Xia, J. Zhao, T. Wang, L. Song, H. Gong, H. Guo, B. Gao, $\mathrm{X}$. Fan and J. He, Anchoring ceria nanoparticles on graphene oxide and their radical scavenge properties under gamma irradiation environment, Phys. Chem. Chem. Phys, 2017, 19, 16785-16794.

35 A. Bedar, R. K. Lenka, N. Goswami, V. Kumar, A. K. Debnath, D. Sen, S. Kumar, S. Ghodke, P. K. Tewari, R. C. Bindal and S. Kar, Polysulfone-Ceria Mixed-Matrix Membrane with Enhanced Radiation Resistance Behavior, ACS Appl. Polym. Mater., 2019, 1, 1854-1865.

36 A. Bedar, N. Goswami, A. K. Singha, V. Kumar, A. K. Debnath, D. Sen, V. K. Aswal, S. Kumar, D. Dutta, B. Keshavkumar, S. Ghodke, R. Jain, B. G. Singh, P. K. Tewari, R. C. Bindal and S. Kar, Nanodiamonds as a stateof-the-art material for enhancing the gamma radiation resistance properties of polymeric membranes, Nanoscale Adv., 2020, 2, 1214-1227.

37 J. Ma, Y. Zhao, Z. Xu, C. Min, B. Zhou, Y. Li, B. Li and J. Niu, Role of oxygen-containing groups on MWCNTs in enhanced separation and permeability performance for PVDF hybrid ultrafiltration membranes, Desalination, 2013, 320, 1-9.

38 J.-H. Kim and K.-H. Lee, Effect of PEG additive on membrane formation by phase inversion, J. Membr. Sci., 1998, 138, 153-163.

39 V. Vatanpour, S. S. Madaeni, R. Moradian, S. Zinadini and B. Astinchap, Fabrication and characterization of novel antifouling nanofiltration membrane prepared from oxidized multiwalled carbon nanotube/polyethersulfone nanocomposite, J. Membr. Sci., 2011, 375, 284-294.

40 S. Bano, A. Mahmood, S.-J. Kim and K.-H. Lee, Graphene oxide modified polyamide nanofiltration membrane with improved flux and antifouling properties, J. Mater. Chem. A, 2015, 3, 2065-2071.

$41 \mathrm{~J}$. Brown and J. O'Donnell, Effects of gamma radiation on two aromatic polysulfones. II. A comparison of irradiation at various temperatures in air-vacuum environments, J. Appl. Polym. Sci., 1979, 23, 2763-2775. 
42 C. Ong, P. Goh, W. Lau, N. Misdan and A. Ismail, Nanomaterials for biofouling and scaling mitigation of thin film composite membrane: A review, Desalination, 2016, 393, 2-15.

43 G. Azimi, R. Dhiman, H.-M. Kwon, A. T. Paxson and K. K. Varanasi, Hydrophobicity of rare-earth oxide ceramics, Nat. Mater., 2013, 12, 315.

44 E. Eren, A. Sarihan, B. Eren, H. Gumus and F. O. Kocak, Preparation, characterization and performance enhancement of polysulfone ultrafiltration membrane using PBI as hydrophilic modifier, J. Membr. Sci., 2015, 475, 1-8.

45 D. J. Hill, K. Milne, J. H. O'Donnell and P. J. Pomery, A recent advance in the determination of scission and cross-linking yields of gamma-ray irradiated polymers, ACS Publications, 1996.
46 O. Rozhin, A. Ferrari and W. I. Milne, Nanomaterial polymer compositions and uses thereof, US Pat., 8323789, 2012.

47 U. Maitra, K. E. Prasad, U. Ramamurty and C. Rao, Mechanical properties of nanodiamond-reinforced polymer-matrix composites, Solid State Commun., 2009, 149, 1693-1697.

48 A. P. Pêgo, D. W. Grijpma and J. Feijen, Enhanced mechanical properties of 1, 3-trimethylene carbonate polymers and networks, Polymer, 2003, 44, 6495-6504.

49 S. Prasadh and R. C. W. Wong, Unraveling the mechanical strength of biomaterials used as a bone scaffold in oral and maxillofacial defects, Oral Sci. Int., 2018, 15, 48-55.

50 M. Siddiqui, A. Arif and S. Bashmal, Permeability-selectivity analysis of microfiltration and ultrafiltration membranes: Effect of pore size and shape distribution and membrane stretching, Membranes, 2016, 6, 40. 